\author{
BRAZILIAN JOURNAL \\ $\mathrm{OF}$ \\ RADIATION SCIENCES \\ 09-01A (2021) 01-15
}

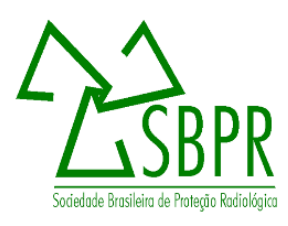

\title{
Influence of contrast injection flux on the outcome of the angiotomography for the diagnosis of pulmonary embolism
}

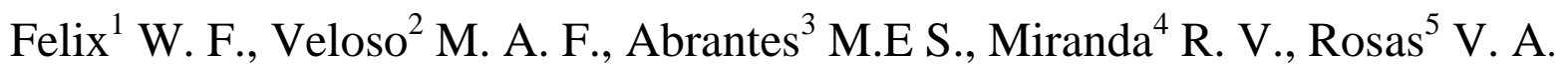 \\ ${ }^{1}$ Hospital das Clínicas (UFMG) - Unidade de Diagnóstico por Imagem
}

Av. Professor Alfredo Balena, 110.

30130-100, Belo Horizonte, MG, Brasil, Brazil

warleyferreirafelix@gmail.com

${ }^{2}$ Universidade Federal de Minas Gerais (UFMG) - Departamento de Engenharia Nuclear (DEN)

Av. Antônio Carlos, 6627 Campus UFMG

31.270-901 - Belo Horizonte, MG, Brazil

${ }^{3}$ Faculdade Ciências Médicas de Minas Gerais (FCMMG)

Pós-Graduação em Higiene Ocupacional/Pós-Graduação em Radioproteção

Alameda Ezequiel Dias, 275. $2^{\circ}$. andar

30130-110 - Belo Horizonte, MG, Brazil

${ }^{4}$ Hospital Erasto Gaertner

Especialização em Dosimetrista para Radioterapia

Rua Dr. Ovande do Amaral, 201.

81520-060 -Curitiba, PR, Brazil

${ }^{5}$ Universidade Federal de Minas Gerais (UFMG) - Curso Superior de Tecnologia em Radiologia

Av. Prof. Alfredo Balena, 190 - Campus SAÚDE

30130-100 - Belo Horizonte, MG, Brazil 


\section{ABSTRACT}

With the development of computed tomography, tomography examinations have been replacing other modalities of imaging tests. Computed tomography angiography to pulmonary thromboembolism, for example, has been replacing pulmonary scintigraphy of ventilation/perfusion and angiography of pulmonary vessels. But angiotomography to the pulmonary thromboembolism is a complex examination, where factors such as scanning time, contrast injection flow, venous access caliber, venous access puncture site, use of the contrast injector, automatic trigger parameters, among others, interfere in the outcome of exam in the studied population. In this study, we performed the contrast ratio $\left(\mathrm{R}_{\mathrm{Z}} \mathrm{C}\right)$, relative the opacification of contrast in the trunk of the pulmonary artery and the descending aorta, which may vary according to the injection protocol used, determined by the flow of contrast injection $(\mathrm{ml} / \mathrm{s})$ associated with the automatic trigger $(\mathrm{HU})$ parameters of the density reading in automatic mode of the equipment. For the injection of manual contrast, and its mean and standard deviation of $\mathrm{R}_{\mathrm{Z}} \mathrm{C}(\mathbf{2 . 6 6} \pm 3.56)$, for the flow $(\mathrm{ml} / \mathrm{s})$ and automatics reading (HU) protocols the means and standard deviations $R_{\mathrm{Z}} \mathrm{C}$ consecutively are: $3.5 \mathrm{ml} / \mathrm{s}$ and $90 \mathrm{HU}(3.68 \pm 2.79)$; 3.5 $\mathrm{ml} / \mathrm{s}$ and $70 \mathrm{HU}(1.90 \pm 0.72) ; 4.0 \mathrm{ml} / \mathrm{s}$ and $70 \mathrm{HU}(1.98 \pm 0.56) ; 3.0 \mathrm{ml} / \mathrm{s}$ and $80 \mathrm{HU}(2.15 \pm 0.89) ; 3.5 \mathrm{ml} / \mathrm{s}$ and $80 \mathrm{HU}(1.50 \pm 0.36) ; 4.0 \mathrm{ml} / \mathrm{s}$ and $80 \mathrm{HU}(3.91 \pm 3.22) ; 4.5 \mathrm{ml} / \mathrm{s}$ and $80 \mathrm{HU}(4.69 \pm 4.82) ; 5.0 \mathrm{ml} / \mathrm{s}$ and $80 \mathrm{HU}$ (4.27 \pm 3.78). The technique with the larger result in the average level of $R_{Z} C$ was the one that used a flow of $4.5 \mathrm{ml} / \mathrm{s}$ and automatic trigger in $80 \mathrm{HU}$.

Keywords: computed tomography, Computed tomography angiography for TEP, Flux, Contrast ratio, Dose optimization 


\section{INTRODUCTION}

With advances in image resolution and scanning time by computed tomography (CT) today, many imaging tests that were considered gold standard are being replaced by tomography examinations, either by cost, accessibility or being less invasive in relation to the other methods $[1,2]$.

Computed tomography angiography (CTA) for the diagnosis of pulmonary thromboembolism (TEP) has been replacing in most cases, angiography of pulmonary vessels and pulmonary ventilation and perfusion scintigraphy, mainly because it is less invasive and low costly, besides presenting diagnostic capacity similar to the others methods $[3,4]$.

In Brazil and other Latin American countries there is a considerable lack of epidemiological data on venous thromboembolism. Between the year 1989 and 2010, approximately 93.000 deaths caused by thromboembolism have been reported. Knowing the Brazilian reality, the study points out that factors such as inequality in access to health care, the quality of services provided in health care and the difficulties of a clinical diagnosis for TEP that contribute to a possible underestimation of the mortality rates by TEP, fact reinforced by the low rates of mortality for TEP in Brazil compared to the United States and Europe [5, 6].

It is estimated that in the United States, there are more than 520.000 cases of TEPs and around 290.000 fatal cases occur annually. There are undiagnosed cases as a consequence of nonspecific symptoms, such as chest pain, shortness of breath, tachycardia among others, which are confused with other pulmonary and cardiac disorders $[7,8]$.

When looking for care services, patients with suspected TEP should be submitted to a clinical investigation, with application of clinical decision questionnaires that stratify the specific risk for TEP and laboratory tests. With the association of the results of the clinical evaluation, the questionnaires and the laboratory tests, the decision is made of the need for complementary tests to establish the diagnosis [9].

The lack of standardization and optimization criteria in medical exposures, according to Brazil, can generate discrepancies in the results of the exams, because where there are no basic criteria or standardization such as the test without the use of the contrast injector, with venous accesses with a 
smaller caliber than recommended and lower injection flow, puncture site access different from the recommended one among others, it is difficult to accomplish out an accurate diagnosis [10].

The search for optimization of the exams in which the level of opacification the structure of interest is early or late in relation to the ideal point, provides information with a technical-scientific basis to adjust the procedures and protocols for the performance of CTA for TEP in a standardized form. Decreasing the repetition of the exams and consequently reducing the doses of radiation provided to the patient [10].

In this scenario, this study was carried out to evaluate the techniques for accomplishment CTA exam for TEP in a public hospital in Belo Horizonte - MG, raising and characterizing the data that make the implementation of CTA for TEP of metrological parameters to indicate the technique of performing the exam that presents to better investigate the structures of interest and to clearly visualize such structures so that the investigation is conclusive.

\section{MATERIALS AND METHODS}

In this context, the different techniques of CTA for TEP exams were analyzed in a public hospital in Belo Horizonte to determine the best method to be followed, in order to reduce the number of exams with indeterminate diagnoses due to the low contrast of the structures of interest. This study was approved both by the Research Ethics Committee/UFMG and by the Hospital's Teaching and Research Department (CAAE- 86446218.4.1001.5149).

\subsection{The CTA for TEP exam}

The CTA for TEP is a scanning of the patient's chest by means of a CT, simultaneously with the automated injection of iodinated contrast for the purpose of contrasting the pulmonary artery and its branches, evidencing or not the presence of thrombus that obstruct the blood circulation in the lung.

For the accomplishment of CTA for TEP examination was used Toshiba ${ }^{\circledR}$ CT scanner with 64 rows which began operating in 2010 and two Medrad ${ }^{\circledR}$ power injection contrast media but with the 
same contrast injection protocol performance characteristics, was used to perform CTA for TEP exams.

\subsection{Technical characteristics of the exam for CTA for TEP and its parame- ters that constitute the research}

The parameters established and pre-set of the institution's routine protocols for CTA for TEP examinations are:

- Examination in the caudecranial direction covering all pulmonary area;

- automatic trigger ( surestart $^{1}$ ) programming for the automatic start of CTA for TEP when the density of the structure of interest reaches 80 Hounsfield Unit (HU);

- $\quad$ Voltage $120 \mathrm{kV}$ fixed;

- Modulated electric current;

- The $360^{\circ}$ rotation of the X-ray tube around the examination table is 0.5 second;

- The ratio between table dislocation, X-ray tube rotation and slice thickness (spiral pitch is 0.828);

- without command for patient apnea.

\subsection{Methods of accomplishment the examination for CTA for TEP}

The CTA for TEP protocol was initially setup with $90 \mathrm{HU}$ in the surestart, and the recommendations of the injector manufacturer are for the use of a venous access per plastic cannula device of at least 18 gauge and injection flow of venous contrast of $3.5 \mathrm{ml} / \mathrm{s}$ [12]. With the initial configuration, it was observed that the tests had low staining in the structure of interest, and attempts were made to modify the protocol, mainly in relation to contrast injection flow and surestart, to try to improve the level of contrast ratio the structures of interest. These attempts did not have the expected effects, then the radiologists and radiology residents did a bibliographic

\footnotetext{
${ }^{1} \mathrm{CT}$ - Density reading tool in HU (Toshiba ${ }^{\mathbb{B}}$ ) and responsible for the automatic start of the examination
} when reaching the programmed density reading [11]. 
review on angiotomographies and CTA for TEP, with changes in the values flow of injection and automatic start of the exam. The current configuration of the protocol it is with surestart of the exam at $80 \mathrm{HU}$ and flow of not less than $4.0 \mathrm{ml} / \mathrm{s}$.

\subsection{Image analysis program}

The Horos computer program was used to analyze the tomographic images. Horos is an open source computer program, and its main purposes are to visualize medical images, 3D rendering, multiplanar reconstructions and curves. One of its main restrictions is the lack of licensing by the Food and Drug Administration (FDA) for use in medical diagnostics, however it is widely used in the medical environment as a diagnostic aid. The program is licensed by the GNU Lesser General Public License, which is approved by the Free Software Foundation [13].

\subsection{Image analysis}

The image analysis methodology will be performed by comparing the opacification in the pulmonary artery and aorta, fig. 1 . In the same image, where a density reading tool ellipses in green (ROI) will be generated in HU to compare the averages of the two structures.

Figure 1: Contrast ratio

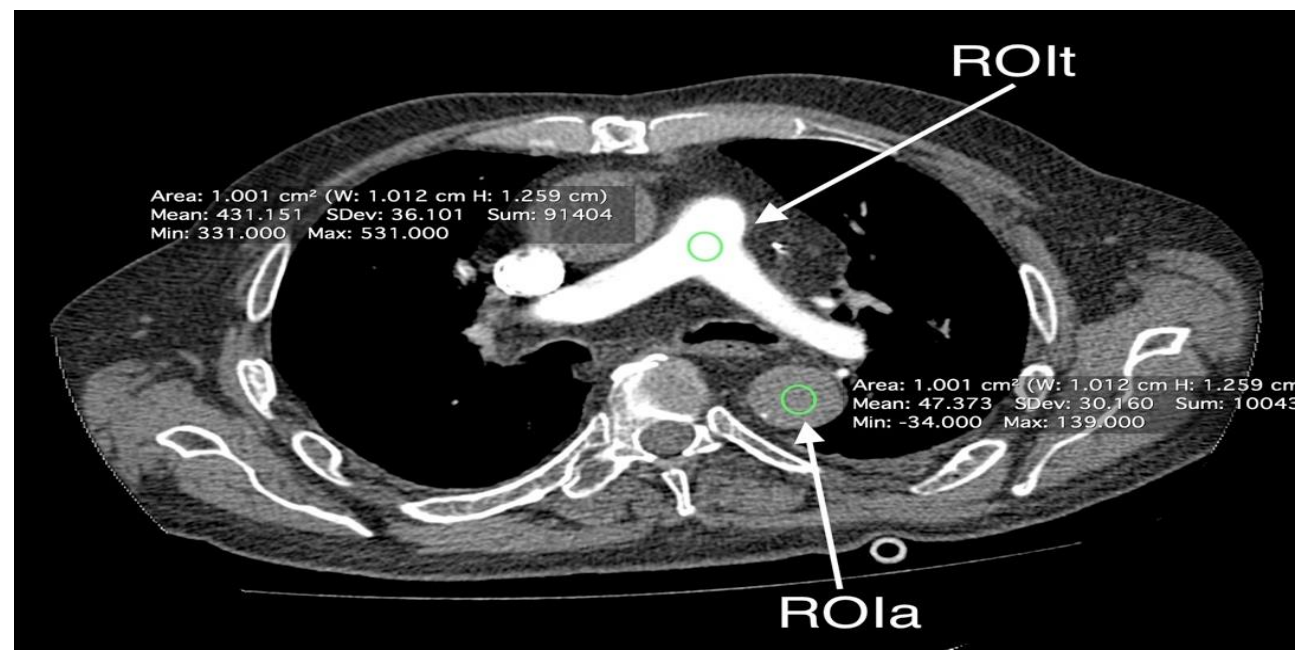

Source: Own 
The comparison will be done by selecting the image that best visualizes the pulmonary artery and positioned an ROI in the trunk of this artery $\left(\mathrm{ROI}_{\mathrm{t}}\right)$ and in the same image will be positioned another ROI of size and shape equal to the previous one fig. 1 In the descending aorta $\left(\mathrm{ROI}_{\mathrm{a}}\right)$ establishing the contrast ratio $(\mathrm{RzC})$ between the two areas according to the equation (1) below.

$$
\mathrm{ROI}_{\mathrm{t}} / \mathrm{ROI}_{\mathrm{a}}=\mathrm{R}_{\mathrm{Z}} \mathrm{C}
$$

The contrast ratio (RzC) was the form found to compare the level of pulmonary artery contrast with the aorta that ideally should not be opacification.

\subsection{The contrast and opacification level}

The tomography department uses non-ionic iodinated contrast in $50 \mathrm{ml}$ vials with an iodine concentration of $300 \mathrm{mg} / \mathrm{ml}$.

The level of contrast of the structure of interest for CTA for TEP should be between 300 and $350 \mathrm{HU}$ so that the radiologist responsible for the report can confirm or refute the presence of TEP [14]. Another recommendation is the use of contrast with iodine concentration of $350 \mathrm{mg} / \mathrm{ml}$ or higher $[15,16]$.

\section{RESULTS AND DISCUSSIONS}

From the beginning of the CTA for the diagnosis of TEP, to the present day these tests are not performed in a standardized form. Modifications in the way of execution are according to the experience of the technician who is conducting the examination, or following the advice of the radiologist responsible.

The variations of achievement in the techniques of the exams happen basically for three reasons:

- The adaptation of the protocol of the tomograph by modifying the HU value of the surestart for the purpose of improving the quality of the examination or increasing the injection flow; 
- Decrease in injection flow when the access caliber is smaller than recommended;

- To accomplishment the examination manually by defective in the contrast injector.

This variation in the realization technique also produces a variety of reasoning results as shown in table 1 and graph 1.

Table 1: Mean opacification for flow.

\begin{tabular}{cccc}
\hline & \multicolumn{2}{c}{ Statistics } \\
Flow $\left(\mathbf{m l . s}^{-\mathbf{1}}\right) /$ & Samples $^{*}$ & $\mathbf{R}_{\mathbf{Z}} \mathbf{C}$ & SD $^{* *}$ \\
\hline Surestart $(\mathbf{H U})$ & 5 & 2,66 & 3,56 \\
\hline Manual injection & 3 & 2,15 & 0,89 \\
$3,0 / 80$ & 3 & 1,90 & 0,72 \\
$3,5 / 70$ & 3 & 1,50 & 0,36 \\
$3,5 / 80$ & 19 & 3,68 & 2,79 \\
$3,5 / 90$ & 2 & 1,98 & 0,56 \\
$4,0 / 70$ & 389 & 3,91 & 3,22 \\
$4,0 / 80$ & 67 & 4,69 & 4,82 \\
$4,5 / 80$ & 7 & 4,27 & 3,78 \\
$5,0 / 80$ & & &
\end{tabular}

*Exams performed under the same conditions as injection contrast flow and surestart **SD -standard deviation [17] 
Graph 1: Contrast ratio by flow

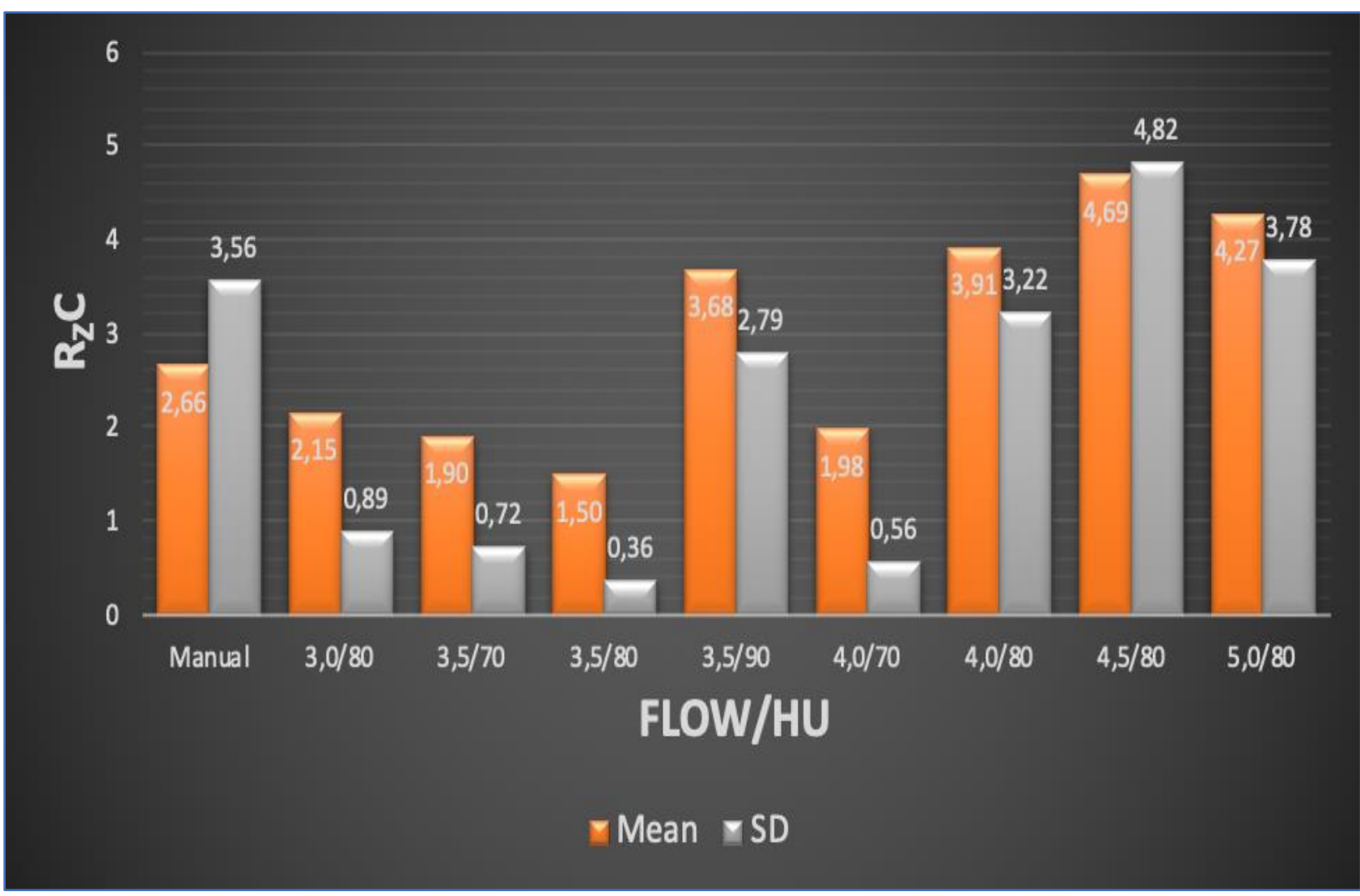

By analyzing the results obtained from the average test results, the protocol with the larger result at the mean level of opacification is the one that uses the injection flow of $4.5 \mathrm{ml} / \mathrm{s}$ and the density of $80 \mathrm{HU}$ for surestart.

Based on the staining of the structure of interest, CTA for TEP angiography can be classified as precocious, fig. 2, structure of interest (long red arrow) with low contrast where the contrast is insufficient for the diagnosis, ideal fig. 3, where the contrast in the structure to be studied is well visualized without overlapping other structures with close contrast, and late fig. 4, where the contrast reached structures (short re arrow) that overlap the ideal, making diagnosis difficult. 
Figure 2: Precocius CTA for TEP

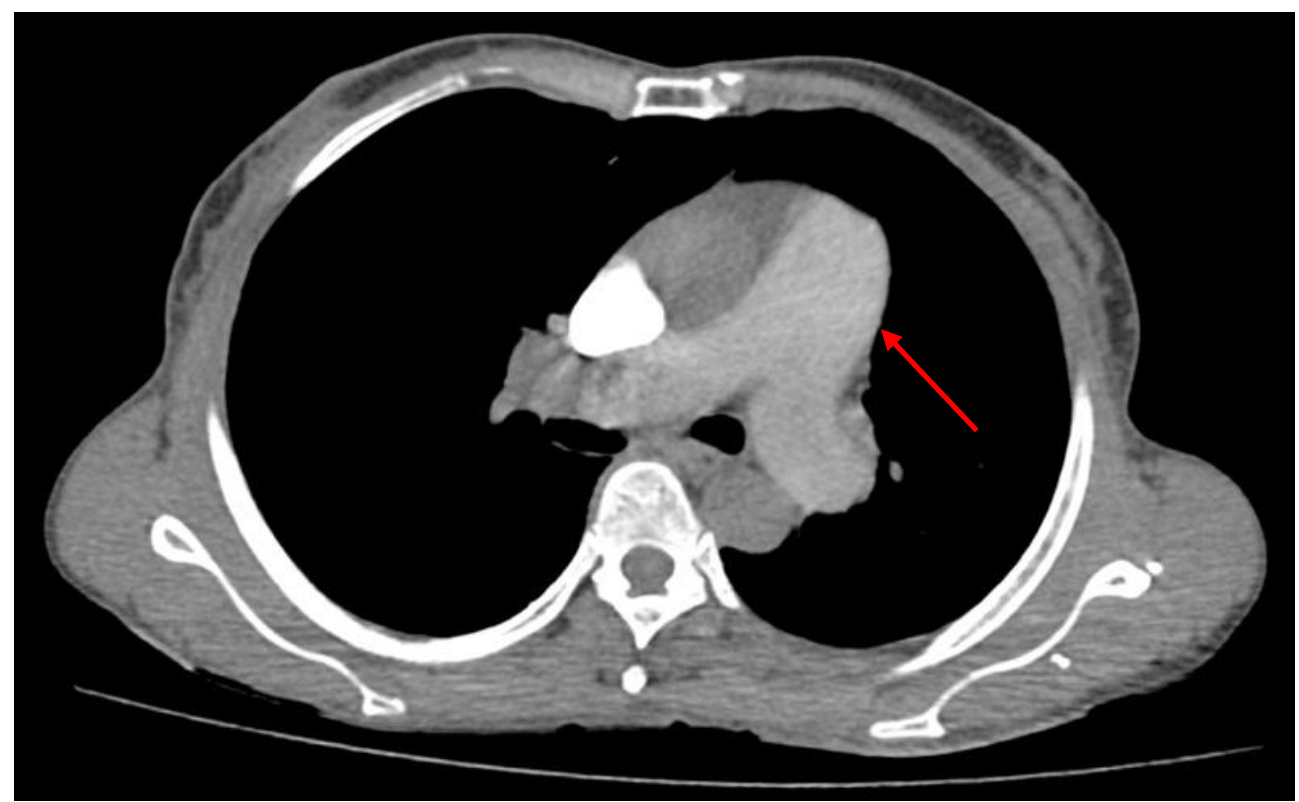

Source: Own

Figure 3: Ideal CTA for TEP

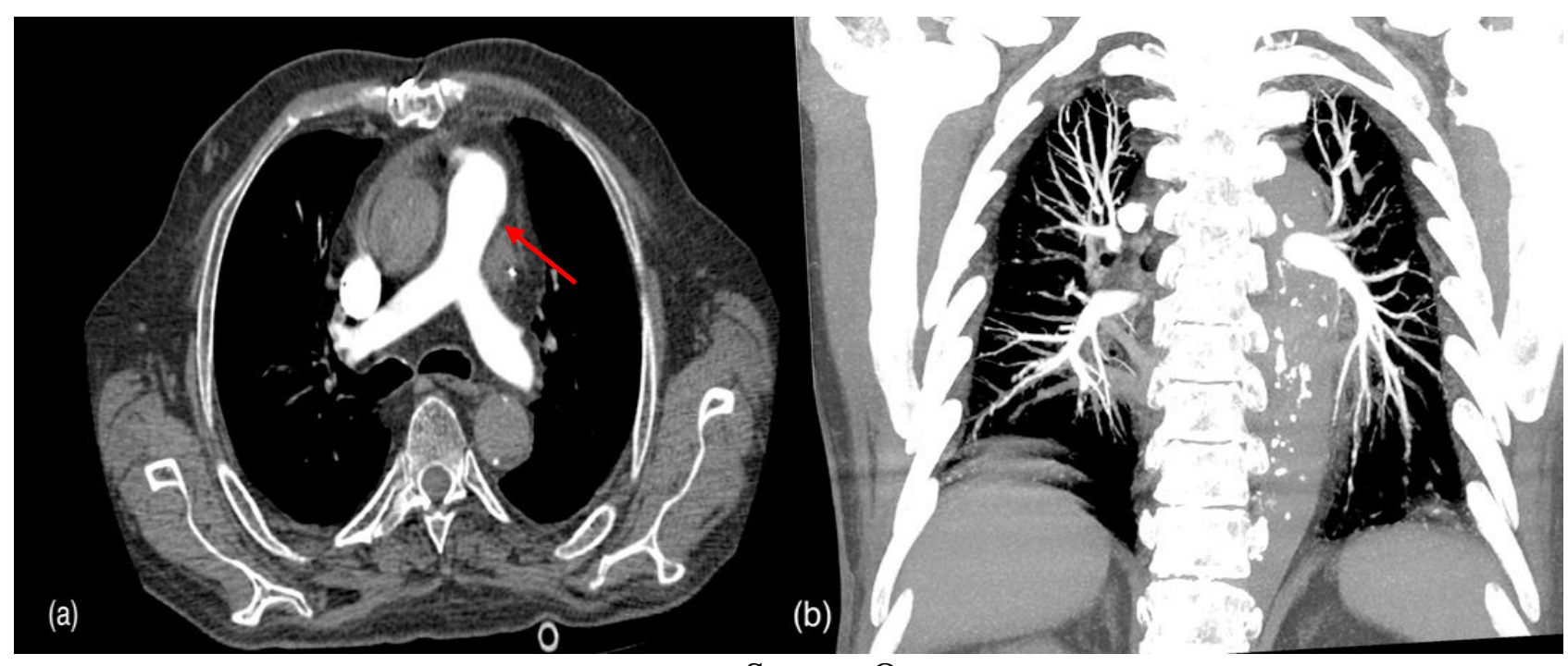

Source: Own

In the fig. 3 (a) structure of interest with ideal contrasts (red arrow); fig. 3 (b) reformatting in maximum intensity projection (MIP). 
Figura 4: Late CTA for TEP

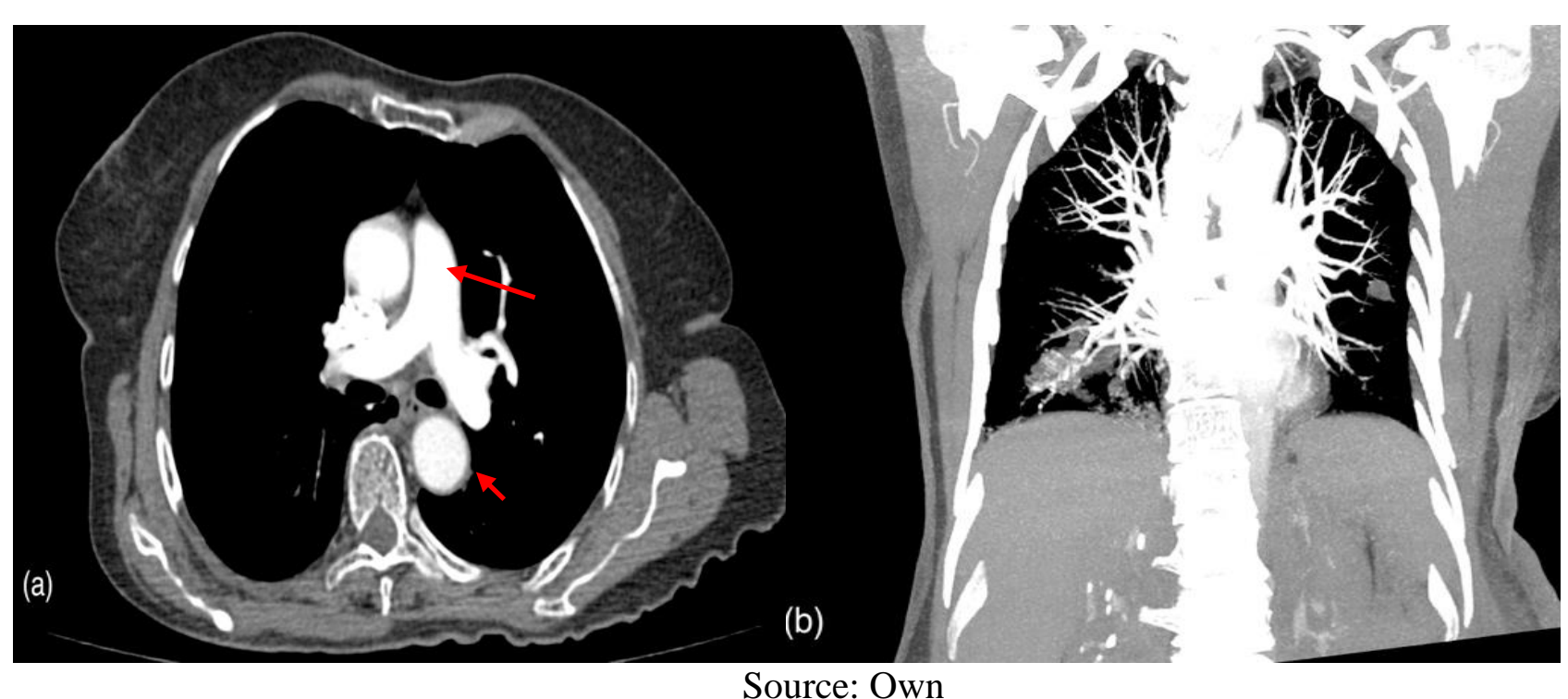

In the fig. 4 (a) structure of interest with contrasting (long red arrow) and high contrasting structure that is not of interest (short red arrow); fig. 4 (b) reformatting in maximum intensity projection (MIP). 


\section{CONCLUSIONS}

It is verified that the selection of the appropriate technique plays a fundamental role in the outcome of CTA for TEP, greatly contributing to the quality of the examination to establish a definitive diagnosis to the patient, avoiding the repetition of examinations or even if it is submitted to other tests in radiology the dose of radiation to which the patient may be exposed.

The technique that presents the larger contrast ration of the structure of interest is the use of the flow of $4.5 \mathrm{ml} / \mathrm{s}$ and an surestart configured in $80 \mathrm{HU}$ reaching a mean of contrast ratio of $4.69 \pm$ 4.82 an increase when we compared the results of the mean $\mathrm{R}_{\mathrm{Z}} \mathrm{C}$ of the techniques used at the beginning of CTA for TEP at the hospital where the study was performed, which was the $3.5 \mathrm{ml} / \mathrm{s}$ contrast injection flow technique with surestart $90 \mathrm{HU}$, obtaining a mean level of contrast ratio of $3.68 \pm 2.79$.

Another important fact is that the techniques that do not establish an adequate ratio of contrast, making it impossible for the radiologist to establish a diagnosis, are abolished in order to reduce inconclusive exams, techniques such as manual injection of contrast that presents an $\mathrm{R}_{\mathrm{Z}} \mathrm{C}$ of $2.66 \pm$ 3.56 and other techniques that did not reach the minimum level of contrast established by the bibliography.

There are also other providence that the department of computed tomography can implement in order to improve the overall quality of CTA for TEPs, such as the acquisition and use of contrasts with higher iodine concentration, improving the level of opacification the structure of interest and even decreasing the amount of contrast used in patients, reducing costs and the risks of adverse effects through the use of contrast, establish minimum parameters for the realization of CTA for TEPs and guide the clinical staff of the hospital of the importance of observing these conditions for quality assurance diagnosis and reduction of dose of ionizing radiation in the patient by repetition of exams. 


\section{ACKNOWLEDGMENTS}

To the Hospital das Clínicas of the Federal University of Minas Gerais, in particular to the Department of Diagnostic Imaging for enabling the execution of this work.

To the Department of Nuclear Engineering of the School of Engineering of the Federal University of Minas Gerais, for educational support.

To my advisers, Profa. Dr. Maria Auxiliadora Fortini Veloso and Prof. Dr. Marcos Eugênio Silva Abrantes for the patience and support offered to me.

To Technologists in Radiology Ramon Vitor de Miranda e Víctor Araújo Rosas, for the support and assistance in this research. 


\section{REFERENCES}

[1] NÓBREGA, Almir Inácio da. Manual de tomografia Computadorizada. Atheneu, 2005.

[2] KONSTANTINIDES, Stavros et al. 2014 ESC guidelines on the diagnosis and management of acute pulmonary embolism. European heart journal, p. ehu283, 2014. <https://doi.org/10.1093/eurheartj/ehu283>. Last accessed: 30 abr. 2017.

[3] STEIN, Paul D. et al. Multidetector computed tomography for acute pulmonary embolism. New England Journal of Medicine, v. 354, n. 22, p. 2317-2327, 2006. <DOI:10.1056/NEJMoa052367> Last accessed: 04 mar. 2017.

[4] SILVA, I. S. C.; MULLER, Nestor L. Diagnóstico por imagem do tromboembolismo pulmonar agudo. J Bras Pneumol, v. 30, n. 5, p. 474-9, 2004.

<http://www.scielo.br/pdf/jbpneu/v30n5/v30n5a12> Last accessed: 16 mar. 2017.

[5] DARZE, Eduardo Sahade et al. Mortalidade por embolia pulmonar no Brasil entre 1989 e 2010: disparidades regionais e por gênero. Arq Bras Cardiol [revista eletrônica], p. 4-12, 2016. DOI 10.5935/abc.20160001. <http://www.scielo.br/pdf/abc/2015nahead/pt_0066-782X-abc20160001.pdf>. Last accessed: 10 set. 2018.

[6] ABC - Arquivo Brasileiro de Cardiologia. Mortalidade por embolia pulmonar no Brasil entre 1989 e 2010: disparidades regionais e por gênero. Arq Bras Cardiol [revista eletrônica], p. 4$12,2016$.

[7] NGC - National Guideline Clearinghouse. Guideline summary: ACR Appropriateness Criteria ${ }^{\circledR}$ acute chest pain - suspected pulmonary embolism. In: National Guideline Clearinghouse (NGC) [Web site]. Rockville (MD): Agency for Healthcare Research and Quality (AHRQ); 2016. < DOI:10.1097/RTI.0b013e31823efeb6>. Last accessed 06 mar. 2017.

[8] ON CARDIAC, Expert Panels et al. ACR Appropriateness Criteria ${ }^{\circledR}$ Acute Chest PainSuspected Pulmonary Embolism. Journal of the American College of Radiology, v. 14, n. 5, p. S2-S12, 2017. < doi.org/10.1016/j.jacr.2017.02.027 > Last accessed 21 maio 2017.

[9] VOLPE, G. J., Joaquim, L. F., Dias, L. B., Menezes, M. B., \& Moriguti, J. C.Tromboembolismo pulmonar. Medicina (Ribeirao Preto. Online), v. 43, n. 3, p. 258-271, 2010. <http://dx.doi.org/10.11606/issn.2176-7262.v43i3p258-271>. Last accessed: 06 Out. 2016. 
[10] BRASIL; MINISTÉRIO DA SAÚDE, SECRETARIA DE VIGILÂNCIA SANITÁRIA.

Diretrizes de proteção radiológica em radiodiagnóstico médico e odontológico: Portaria $\mathrm{n}^{\circ} 453$. 1998.

[11] HOFER, Matthias. Tomografia Computadorizada - Manual prático de ensino. Ed. Revinter, 2005. ISBN 85-7309-855-4

[12] BAE, K. T. Intravenous contrast medium administration and scan timing at CT: considerations and approaches 1. Radiology, v. 256, n. 1, p. 32-61, 2010.

<https://doi.org/10.1148/radiol.10090908>. Last accessed: 16 mar. 2017.

[13] HOROS PROJECT (2015). DICOM image viewing and measuring. [Horos v.2.02]. http://www.horosproject.org/. Last accessed: 26 jan. 2017

[14] HALPERN, Ethan J. Triple-rule-out CT angiography for evaluation of acute chest pain and possible acute coronary syndrome. Radiology, v. 252, n. 2, p. 332-345, 2009.

<https://doi.org/10.1148/radiol.2522082335 >. Last accessed: 21 abr. 2017

[15] ACR MANUAL ON CONTRAST MEDIA - ACR Committee on Drugs - and Contrast Media 2016. < https://www.acr.org/Quality-Safety/Resources/Contrast-Manual >. Last accessed: 16 mar. 2017.

[16] AMERICAN COLLEGE OF RADIOLOGY et al. ACR-NASCI-SIR-SPR practice parameter for the performance and interpretation of body computed tomography angiography (CTA) 2017. < https://www.acr.org/-/media/ACR/Files/Practice-Parameters/Body-CTA.pdf>. Last accessed: 30 mar.2017

[17] GOMES, F. P. Curso de estatística experimental. 14. ed. Piracicaba: Nobel, 477 p., 2000 